\title{
Pandemics and Systemic Discrimination: Technology-Facilitated Violence and Abuse in an Era of COVID-19 and Antiracist Protest
}

\author{
Jane Bailey, Asher Flynn, and Nicola Henry
}

\begin{abstract}
Technology-facilitated violence and abuse is a truly global problem. As the diverse perspectives and experiences featured in this book have shown, the deep entanglement between technologies, inequality, marginalization, abuse, and violence require multi-faceted and collaborative responses that exist within and beyond the law. When this chapter was written, society was (and continues to be) facing an unprecedented challenge in COVID-19 - a global pandemic. At the same time, a renewed focus on racist police and civilian violence has occurred following the killings of George Floyd, Ahmaud Arbery, and Breonna Taylor in the United States. As we describe in this chapter, these two major moments are ongoing reminders of the profound social inequalities within our global communities, which are grounded in systemically discriminatory oppressions and their intersections. This chapter draws together some thoughts on technology-facilitated violence and abuse in an era of COVID-19 and antiracist protest. It explores these within the context of the book as a whole, highlighting the importance for improved understanding of, and responses to, technology-facilitated violence and abuse as part of a broader push for social justice.
\end{abstract}

Keywords: Technology-facilitated violence and abuse; COVID-19; racism; pandemic; systemic discrimination and oppression; police violence

The Emerald International Handbook of Technology-Facilitated Violence and Abuse, 787-797 Copyright (C) 2021 Jane Bailey, Asher Flynn, and Nicola Henry

Published by Emerald Publishing Limited. This chapter is published under the Creative

Commons Attribution (CC BY 4.0) licence. Anyone may reproduce, distribute, translate and create derivative works of these chapters (for both commercial and non-commercial purposes), subject to full attribution to the original publication and authors. The full terms of this licence may be seen at http://creativecommons.org/licences/by/4.0/legalcode.

doi:10.1108/978-1-83982-848-520211057 


\section{Introduction}

The worst and the best of humanity are being graphically showcased on a daily basis as we prepare this manuscript for submission. The global COVID-19 pandemic and renewed focus on racist police and civilian violence following the killings of George Floyd, Ahmaud Arbery, and Breonna Taylor ${ }^{1}$ in the United States (US) are ongoing reminders of the lasting and profound social inequalities that plague our global communities. These are social inequalities that are grounded in systemically discriminatory oppressions such as racism, misogyny, colonialism, homophobia, transphobia, ableism, and their intersections. The task of producing a collection about technology-facilitated violence and abuse (TFVA) could easily have been overwhelmed by this unprecedented and chaotic context. We are extremely grateful to our contributors and to those whose intended contributions were rendered impossible by the circumstances that surround us. We deeply appreciate their stalwart efforts and perseverance, which ultimately made this international, intersectional, intersectoral, and interdisciplinary collection happen, notwithstanding the fact that the odds were stacked against it. We say this not simply because we believe in this project but also because we believe that these pandemics of both disease and racist violence render ever more obvious, the deep entanglement between our technologies and ourselves in ways that make the diverse perspectives and experiences of TFVA featured in this book more important than ever.

\section{COVID-19 and Racist Police Violence: Spotlight on Systemic Discrimination}

COVID-19 and racist police violence are potent reminders of systemic discrimination and violence. And, like TFVA, while they involve and are experienced by individuals, they are part of a collective, structural context that puts members of marginalized communities at greater risk. Emerging international research on COVID-19 indicates that racialized and immigrant, Indigenous, and low-income populations are disproportionately more likely to contract the disease, to experience a severe case of the illness, and to die from it than their nonracialized and nonimmigrant counterparts (Centers for Disease Control and Prevention, 2020; Public Health Ontario, 2020; UK Office for National Statistics, 2020). The higher risk of exposure to illness and death within these communities reflects a variety of outcomes of systemic discrimination, including: living in densely populated/overcrowded conditions due to neighborhood segregation; living on reservations without adequate water and sanitation facilities; living in areas remote from groceries, medical care, and safe transportation; lack of private means of transportation; overrepresentation in prisons, shelters, and detention centers - which is itself a product of systemic discrimination (Blewett, 2020; Centers for Disease Control and Prevention, 2020) - as well as working in often lower paid public-facing essential services (Blewett, 2020). Further, a number of additional studies indicate that the self-isolation requirements associated with the pandemic have contributed to increased levels of domestic violence reporting (see, e.g., Mohler et al., 2020; Powell \& Flynn, 2020; Price, 2020), and escalating violence against women and girls often 
due to confinement with abusive family members and caregivers, and to reduced access to domestic violence and health services, with disproportionate effects on women and girls "facing multiple forms of discrimination" (UN Women, 2020, p. 1).

As the events of COVID-19 continue to unfold, so too have protests against another pandemic, the "pandemic of racism" that led to the recent highly publicized deaths of Black Americans, George Floyd, Ahmaud Arbery, and Breonna Taylor. Mr. Floyd was killed by a white police officer kneeling on his neck for over 8 minutes, ignoring his pleas that he could not breathe (BBC News, 2020c). At Floyd's memorial service, lawyer Benjamin Crump stated that "it was 'not the coronavirus pandemic that killed George Floyd. It was that other pandemic ... The pandemic of racism and discrimination"” (BBC News, 2020c). Floyd's killing, like the killings of Arbery and Taylor (which occurred earlier in 2020), was captured on videos that were widely circulated online (McLaughlin, 2020), sparking Black Lives Matter protests internationally that aimed not only to raise public awareness of Floyd's death but also to place it, and the deaths of Arbery and Taylor, among others, in the larger and long-standing context of systemic racism and anti-Black policing in countries around the world (Bonhomme, 2020). Tyra Jean (2020) aptly captures the systemic underpinnings of both the differential impacts of COVID-19 and racist police violence as follows:

Though police brutality and COVID-19 are separate tragedies, they intersect. As with police killings, the COVID-19 death rate is higher among Blacks than the US population overall. The COVID-19 pandemic has shed light on America's deeply rooted structural health inequities. From inadequate access to healthcare to representing a disproportionate share of active frontline essential workers, the U.S. Black population consistently bears the burden of life-threatening consequences due to structural racism and non-inclusive policies throughout multiple institutions.

Public attention is also increasingly being focused on racist police violence against members of other marginalized communities, including Indigenous people in Canada (Britneff, 2020), who are "more than 10 times more likely to have been shot and killed by a police officer in Canada since 2017 than a white person in Canada" (Flanagan, 2020).

The reports relating to the COVID-19 pandemic and racist police violence that are punctuating international headlines as we prepare this manuscript for submission serve as important reminders of the very real impacts of systemic discrimination and violence on the lives of members of marginalized communities. It is important to note that although COVID-19 and racist violence are currently in the news, the systemic discrimination that shapes them is far from new, ${ }^{2}$ particularly for members of marginalized communities whose lived realities are affected by it on a daily basis. While the bases of discrimination may vary from nation to nation, as many of the contributions in this volume powerfully demonstrate, preexisting structures of oppression such as misogyny (see, e.g., Chisala-Templehoff \& Stevenson; Harris \& Woodlock), racism and colonialism (see, e.g., Carlson \& Frazer; Bailey \& Shayan; Novich \& Zduniak), homophobia 
and transphobia (see, e.g., Colliver), and their intersections, frequently play a pivotal role in TFVA. Just like COVID-19, and racist police and civilian violence, TFVA is experienced by individuals, but is shaped by broader systemic forces that demand not only immediate responses but broader, proactive social change.

\section{COVID-19 and Racist Police Violence: Online/ Offline Convergence}

The current pandemic and protests against racist police violence also serve to reinforce the deep interconnection between what might previously have been conceived of as the separate "online" and "offline," or "real" and "cyber" worlds a distinction that many contributions in the book show to be not only untenable, but harmful (see, e.g., Dunn; Gosse). Further, the roles of technology in shaping understandings of, interactions with, and responses to these events helps to highlight the entanglement of technology companies' practices and policies discussed in this book, in this increasingly seamlessly converged reality in which more and more aspects of our lives are made dependent upon digital connectivity (see, e.g., Henry \& Witt). As part of this converged reality, just as a number of chapters have noted in relation to technology-facilitated intimate partner violence and image-based sexual abuse (see, e.g., Louie; Ferreira Lopes; Marganski \& Melander; Slupska \& Tanczer; see also Powell \& Flynn, 2020; Price, 2020), we have seen technology used in the pandemic and protest contexts to both respond to and perpetrate violence and abuse in ways that serve to question, as well as to reentrench, the broader systemic forces at play.

\section{COVID-19: (Mis)information, Online Hate, and Other Technological Dimensions}

Social media has been a central source of information and misinformation relating to COVID-19, with emerging research suggesting that "top-down misinformation from politicians, celebrities, and other prominent figures," while accounting for only a small fraction of false/inaccurate claims, comprises a significant portion of social media engagement (Brennen, Simon, Howard, \& Nielsen, 2020). The spread of misinformation includes false claims about treatments for or prevention of COVID-19 (Ha-Redeye, 2020), inaccurate information about health authorities and their actions (Brennen et al., 2020), conspiracy theories suggesting that a vaccine existed but was being withheld (Oi-Yee Li, Bailey, Huynh, \& Chan, 2020), and that COVID-19 is "a leaked bioweapon, a byproduct of 5G wireless technology and a political hoax" (Caulfield, 2020), among many others. Some of the misinformation suggesting drinking bleach and cow urine, for example, presents immediate physical health risks if followed (Caulfield, 2020).

Other misinformation propagated hatred against Chinese people (and to a lesser extent other racial and ethnic minority groups) by using "discriminating and stigmatizing language against Chinese people" that played on preexisting stereotypes about Chinese lifestyle and eating habits, in order to blame Chinese 
people for the pandemic (Aratani, 2020; Stechemesser, Wenz, \& Levermann, 2020). This online hate speech translated to a growth in reported instances of discrimination, aggression, and racism against people of Asian descent in numerous parts of the globe (see, e.g., Aratani, 2020; Gill, 2020; Shimizu, 2020). Some of the online tactics that have been used during the COVID-19 pandemic resemble the sorts of "othering" techniques discussed by Benjamin Colliver and Elina Vaahensalo in their chapters in this book.

At the same time, digital communication technologies have been heralded for enabling the continuation of numerous activities, such as business meetings, classes (Bailey, Burkell, Regan, \& Steeves, 2020), medical consultations (Favaro \& St Philip, 2020), court hearings (Douglas, 2020), and provision of support services to targets of domestic and sexual violence (see, e.g., Canadian Women's Foundation, 2020; Ottawa Coalition to End Violence Against Women, 2020), without breaking social distancing rules. However, with mass migration of activities to online platforms have emerged new and modified forms of TFVA that often reflect and reentrench preexisting systems of discrimination (Harwell, 2020). Perhaps the most prominent North American example is "Zoombombing" - a practice in which uninvited individuals have exploited security flaws in the Zoom videoconferencing software and/or meeting organizers' lack of awareness of security features in order to make unwelcome interventions in ongoing meetings and classes. Numerous reports indicate that these interventions have included unwanted pornographic, racist, threatening, and/or misogynistic content (see, e.g., Andone, 2020; Redden, 2020). Other forms of TFVA-related content arising in the pandemic context include reported threats and pressures in dating apps for women to break social distancing rules (Iovine, 2020), and expanded accessibility of child sexual abuse material and online sexual exploitation (Europol, 2020).

With the expanded use of digital communications technologies as part of COVID-19, the opportunities for technology companies to collect and make use of data to profile users for the purposes of, among other things, marketing to them, have also expanded (Bailey et al., 2020). Little is known about what exactly is being done with data collected by providers of online videoconferencing software, although information privacy commissioners have expressed concern about these issues (see, e.g., CBC News 2020; Office of the Privacy Commissioner of Canada, 2020). In response to expression of widespread public concern, some platforms have indicated privacy and security are an increasing priority (see, e.g., Zoom, 2020). Even more concerning are reports relating to tracking apps, drones, video surveillance, and other digital technologies being used in countries around the world (including South Korea, Hong Kong, China, and Israel) to, among other things, monitor for compliance with COVID-19 regulations, as well as for indicators of infection (such as elevated body temperature) (Dupont, 2020). While these technologies raise concerns about the possibilities for new forms of state-created TFVA that are of interest to everyone, the historic record of the oversurveillance and profiling of racialized and other marginalized groups in many societies (Gandy, 1993) raises concerning prospects that their privacy-invasive harms will be disproportionately borne by equality-seeking communities. 
COVID-19 has also afforded insight into another dimension of the deep entanglement of technology company business models and practices with TFVA. For example, as Nicola Henry and Alice Witt discuss in their chapter, while considerable ink has been spilled on whether social media platforms can and should remove harmful content, technology companies under COVID-19 displayed a remarkable willingness and capacity to act in relation to certain kinds of misinformation (Newton, 2020). Google searches relating to COVID-19 immediately trigger an alert and appear to prioritize content from more reliable sources, including local health authorities (Newton, 2020). As of May 2020, Facebook's misinformation strategy included the use of AI to flag what they deem to be harmful misinformation, and the use of messages warning users to avoid false information any time they interact with flagged content, as well as providing links to the World Health Organization (Brodwin, 2020). While the efforts of both of these companies have been subject to certain criticisms (see, e.g., Brodwin, 2020; Newton, 2020), the very fact that these efforts are being made acknowledges the degree to which platform design and practices can be used to shape user behavior and interaction, raising important questions about whether, and if so, how such techniques could and should be used in response to other forms of TFVA (in this book, see PenzeyMoog \& Slakoff; Slupska \& Tanczer).

\section{Racist Police Violence: Technological Dimensions}

As with COVID-19, digital communications technologies have played significant roles in relation to racist police violence and protest movements responding to them. Some consider the release of the videos of George Floyd's killing, as well as videos of police and civilian killings of other Black Americans, including Ahmaud Arbery and Breonna Taylor, as important catalysts for global protests and expressions of support for Black Lives Matter (see, e.g., Aratani, 2020; Johnson, 2020). ${ }^{3}$ Further, use of Twitter hashtags including \#BlackLivesMatter and \#IdleNoMore have played prominent and important roles in raising public awareness and inspiring calls for justice for racialized and Indigenous communities. These same platforms, however, have been used by far-right extremists for purposes of perpetuating racism, colonialism, and other discriminatory oppressions, often in a bid to radicalize and recruit new members (Townsend, 2020). They have also been used by mainstream politicians, such as Donald Trump, to attack and ridicule calls for racial justice (Wilke, 2020). And while K-pop fans have taken matters into their own hands using "virtual protesting" tactics to "drown out" alt-right commentary by posting videos of their favorite bands on hashtags such as \#whitelivesmatter (Schatz, 2020), calls for expanded oversight of platform operations continue in a number of countries (see, e.g., Broadcasting and Telecommunications Legislative Review Panel, 2020, pp. 190-198; Townsend, 2020).

Further, as with COVID-19, surveillance technologies are playing concerning roles in relation to protests against racist police violence. For example, recent reports suggest that facial recognition technologies and drones are being used across US cities to surveil Black Lives Matter protestors (Medium, 2020). Some 
technology companies, such as IBM, Amazon, and Microsoft have publicly stated they "won't sell or would at least pause police use of their facial recognition technology until there are federal laws on the matter" (Fowler, 2020). However, some have dismissed such statements as publicity stunts, given technology companies' ongoing interference in efforts by civil rights and privacy advocates to have these technologies banned altogether (Fowler, 2020).

\section{Looking to the Future}

This Handbook has been incubated and will be born into complex and chaotic times defined by historic global pandemics of disease (COVID-19), racism, and (mis)information. These are times in which the entanglements of social, cultural, economic, political, and technological forces in lived experiences around the globe are undeniable, and where careful attention must be paid to the impacts of discriminatory systems such as misogyny, racism, homophobia, transphobia, colonialism, ableism, classism, and their intersections, as well as to perspectives beyond those of us situated in industrialized nations. Mindful of this context, it is in this spirit that we add this collection to the cacophony of voices calling for improved understanding of, and responses to, TFVA.

\section{Acknowledgment}

Thanks to uOttawa JD student Taylor Bain for her research assistance and to the Social Sciences and Humanities Research Council of Canada for funding The eQuality Project, a 7-year initiative co-led by Jane Bailey and Valerie Steeves, which focuses on young people's experiences with privacy and equality in networked environments.

\section{Notes}

1. George Floyd was killed by US police officers in Minneapolis on May 25, 2020 (New York Times, 2020). Ahmaud Arbery was shot in Georgia on February 23, 2020 by two white men while jogging (BBC News, 2020a). On March 13, 2020, Breonna Taylor was shot 8 times and killed at home in bed after police officers broke down her apartment door while purportedly "serving a 'no-knock' warrant for a narcotics investigation" (BBC News, 2020b).

2. It is well established that social determinants of health, including race, gender, socioeconomic status, indigeneity, occupation, homelessness, and incarceration have a profound impact on exposure to, contraction and severity of illness, with social and racial inequity having played a proven role in prior pandemics, such as H1N1 (Public Health Ontario, 2020). Similarly, protests against racist policing have been ongoing for decades in the United States and elsewhere, though there is some hope that this time, lasting change will emerge (Chotiner, 2020).

3. It is important, however, not to overstate the role of the public release of such videos, given that prior release of images of racist police violence have not sparked such broad-based and sustained public activism and outrage. Black Lives Matter cofounder, Opal Tometi, has suggested that pandemic conditions may make this 
situation different. She has noted that people in the United States are "more tender or sensitive to what is going on," not only in relation to police violence, but with respect to the US government's lack of a "plan of action that is dignified and comprehensive ... [and aimed at] the core concerns that the average American has" (Chotiner, 2020).

\section{References}

Andone, D. (2020). FBI warns video calls are getting hijacked. It's called 'Zoombombing'. $C N N$. Retrieved from https://www.cnn.com/2020/04/02/us/fbi-warningzoombombing-trnd/index.html

Aratani, L. (2020). 'Coughing while Asian': Living in fear as racism feeds off coronavirus panic. The Guardian. Retrieved from https:/www.theguardian.com/world/ 2020/mar/24/coronavirus-us-asian-americans-racism

Bailey, J., Burkell, J., Regan, P., \& Steeves, V. (2020). Children's privacy is at risk with rapid shift to online schooling under coronavirus. The Conversation. Retrieved from https://theconversation.com/childrens-privacy-is-at-risk-with-rapid-shifts-toonline-schooling-under-coronavirus-135787

BBC News. (2020a). Ahmaud Arbery: What do we know about the case? Retrieved from https://www.bbc.com/news/world-us-canada-52623151

BBC News. (2020b). Breonna Taylor: Louisville officer to be fired for deadly use of force. Retrieved from https://www.bbc.com/news/world-us-canada-53111709

BBC News. (2020c). George Floyd: 'Pandemic of racism' led to his death, memorial told. Retrieved from https://www.bbc.com/news/world-us-canada-52928304

Blewett, T. (2020). Systemic racism, barriers explain higher rates of COVID-19 among immigrant, non-white communities in Ottawa: Experts. The Ottawa Citizen. Retrieved from https://ottawacitizen.com/news/local-news/systemic-racism-barriers-explain-higher-rates-of-covid-19-among-immigrant-non-white-communitiesin-ottawa-experts/wcm/8c8b3e4a-7b79-48ec-97dd-ca8c9eab1433/

Bonhomme, E. (2020). George Floyd, a survivor's guilt and a global Black Lives Matter. Aljazeera. Retrieved from https://www.aljazeera.com/indepth/opinion/ george-floyd-survivor-guilt-global-black-lives-matter-200620181544441.html

Brennen, J. S., Simon, F. M., Howard, P. N., \& Nielsen, R. K. (2020). Types, sources and claims of COVID-19 misinformation. University of Oxford, Reuters Institute for the Study of Journalism, Oxford Internet Institute, and Oxford Martin School. Retrieved from http://www.primaonline.it/wp-content/uploads/2020/04/COVID19_reuters.pdf

Britneff, B. (2020). 'Disturbing' police violence against Indigenous people will be investigated: Trudeau. Global News. Retrieved from https:/globalnews.ca/news/ 7030052/miller-outraged-police-violence-indigenous-people/

Broadcasting and Telecommunications Legislative Review Panel. (2020). Canada's communications future: Time to act. Retrieved from https://www.ic.gc.ca/eic/site/ 110.nsf/vwapj/BTLR_Eng-V3.pdf/\$file/BTLR_Eng-V3.pdf

Brodwin, E. (2020). Facebook's COVID-19 misinformation campaign is based on research. The authors worry Facebook missed the message. Stat. Retrieved from https://www.statnews.com/2020/05/01/facebooks-covid-19-misinformation-campaignis-based-on-research-the-authors-worry-facebook-missed-the-message/ 
Canadian Women's Foundation. (2020). Signal for help. Toronto, ON: Canadan Women's Foundation. Retrieved from https://canadianwomen.org/signal-for-help/ Caulfield, T. (2020). Pseudoscience and COVID-19 - we've had enough already. Nature. doi:10.1038/d41586-020-01266-Z

CBC News. (2020). Make sure your virtual meetings are secure says Sask. privacy commissioner. Retrieved from https://www.cbc.ca/news/canada/saskatoon/privacyvirtual-meeting-saskatchewan-1.5545672

Centres for Disease Control and Prevention. (2020). COVID-19 in racial and ethnic minority groups. Retrieved from https://www.cdc.gov/coronavirus/2019-ncov/needextra-precautions/racial-ethnic-minorities.html

Chotiner, I. (2020). A Black Lives Matter co-founder explains why this time is different. The New Yorker. Retrieved from https://www.newyorker.com/news/qand-a/a-black-lives-matter-co-founder-explains-why-this-time-is-different

Douglas, H. (2020). Changes to our courts: How COVID-19 is changing the landscape. Slaw. Retrieved from http://www.slaw.ca/2020/03/31/changes-to-our-courtshow-covid-19-is-changing-the-landscape/

Dupont, B. (2020). Covid-19: Les derives possible de surveillance des données personnelles. The Conversation. Retrieved from https://theconversation.com/covid-19les-derives-possibles-de-surveillance-des-donnees-personnelles-139443

Europol. (2020). Pandemic profiteering: How criminals exploit the COVID-19 crisis. Retrieved from pandemic_profiteering-how_criminals_exploit_the_covid-19_crisis. pdf

Favaro, A., \& Philip, E. St. (2020). Ontario implements virtual medical visits in bid to keep doctors, patients safe amid COVID-19. CTV News. Retrieved from https:// www.ctvnews.ca/health/coronavirus/ontario-implements-virtual-medical-visits-inbid-to-keep-doctors-patients-safe-amid-covid-19-1.4853436

Flanagan, R. (2020). Why are Indigenous people in Canada so much more likely to be shot and killed by police? CTV News. Retrieved from https://www.ctvnews.ca/ canada/why-are-indigenous-people-in-canada-so-much-more-likely-to-be-shot-andkilled-by-police-1.4989864

Fowler, G. (2020). Black Lives Matter could change facial recognition forever - If big tech doesn't stand in the way. Washington Post. Retrieved from https:// www.washingtonpost.com/technology/2020/06/12/facial-recognition-ban/

Gandy, O. (1993). The panoptic sort: A political economy of personal information. Boulder, CO: Westview Press

Gill, R. (2020). Asian communities across Canada report rising racist behaviour during COVID-19. Global News. Retrieved from https://globalnews.ca/news/7033253/coronavirus-asian-racism-crisis-canada//

Ha-Redeye, O. (2020). False and misleading claims around COVID. Slaw. Retrieved from http://www.slaw.ca/2020/05/10/false-and-misleading-claims-around-covid/

Harwell, D. (2020). Everybody seems to be using Zoom. But its security flaws could leave users at risk. Washington Post. Retrieved from https://www.washingtonpost.com/ technology/2020/04/02/everybody-seems-be-using-zoom-its-security-flaws-could-leavepeople-risk/

Iovine, A. (2020). Men are harassing women on dating apps to meet up and break social distancing rules. Mashable. Retrieved from https://mashable.com/article/ dating-app-meet-harassment-coronavirus-social-distance/ 
Jean, T. (2020). Black Lives Matter: Police brutality in the era of COVID-19. Syracuse: Lerner Centre for Public Health Promotion. Retrieved from https:// lernercenter.syr.edu/wp-content/uploads/2020/06/Jean.pdf

Johnson, D. (2020). The George Floyd uprising has brought us hope. Now we must turn protest to policy. The Guardian. Retrieved from https://www.theguardian.com/ commentisfree/2020/jun/30/black-lives-matter-protests-voting-policy-change

McLaughlin, E. (2020). Three videos piece together the final moments of George Floyd's life. CNN. Retrieved from https://www.cnn.com/2020/06/01/us/georgefloyd-three-videos-minneapolis/index.html

Medium. (2020). Usage of surveillance drones over Black Lives Matter protests in the USA. Medium. Retrieved from https://mediummagazine.nl/usage-of-surveillancedrones-over-black-lives-matter-protests-in-the-usa/

Mohler, G., Bertozzi, A., Carter, J., Short, M. B., Sledge, D., Tita, G. E., ... Jeffrey Brantingham, P. (2020). Impact of social distancing during COVID-19 pandemic on crime in Los Angeles and Indianapolis. Journal of Criminal Justice, 68. doi: 10.1016/j.jcrimjus.2020.101692

New York Times. (2020). 8 minutes and 46 seconds: How George Floyd was killed in police custody. New York Times. Retrieved from https://www.nytimes.com/2020/ 05/31/us/george-floyd-investigation.html

Newton, C. (2020). Google has been unusually proactive in fighting COVID-19 misinformation. Verge. Retrieved from https://www.theverge.com/interface/2020/3/ 11/21173135/google-coronavirus-misinformation-youtube-covid-19-twitter-manipulated-media-biden

Office for National Statistics. (2020). Coronavirus (COVID-19) related deaths by ethnic group, England and Wales: 2 March 2020 to 10 April 2020. Retrieved from https:// www.ons.gov.uk/peoplepopulationandcommunity/birthsdeathsandmarriages/deaths/ articles/coronavirusrelateddeathsbyethnicgroupenglandandwales/2march2020to10 apri12020

Office of the Privacy Commissioner of Canada. (2020). Privacy tech-know blog: Videoconferencing - Maintain your physical distance, but keep your personal information close. Retrieved from https://www.priv.gc.ca/en/blog/20200501/

Oi-Yee Li, H., Bailey, A., Huynh, D., \& Chan, J. (2020). YouTube as a source of information on COVID-19: A pandemic of misinformation? BMJ Global Health, 5(5). Retrieved from https://gh.bmj.com/content/5/5/e002604

Ottawa Coalition to End Violence Against Women. (2020). Where can survivors of violence still access support during the COVID-19 pandemic in Ottawa? Retrieved from https://www.octevaw-cocvff.ca/covid19-services

Powell, A., \& Flynn, A. (2020). Reports of 'revenge porn' skyrocket during lockdown: We must stop blaming the victims for it. The Conversation. Retrieved from https:// theconversation.com/reports-of-revenge-porn-skyrocketed-during-lockdown-wemust-stop-blaming-victims-for-it-139659

Price, H. (2020). Coronavirus 'revenge porn' surge hits helpline. BBC. Retrieved from https://www.bbc.com/news/stories-52413994

Public Health Ontario. (2020). COVID-19 - what we know so far about ... social determinants of health. Retrieved from https://www.publichealthontario.ca/-/media/ documents/ncov/covid-wwksf/2020/05/what-we-know-social-determinants-health. pdf?la $=$ en 
Redden, E. (2020). 'Zoombombing' attacks disrupt classes. Higher Education. Retrieved from https://www.insidehighered.com/news/2020/03/26/zoombombersdisrupt-online-classes-racist-pornographic-content

Schatz, L. (2020). K-pop fans take over \#WhiteLivesMatter and \#BlueLivesMatter hashtags. Cos Entertainment News. Retrieved from https://consequenceofsound.net/ 2020/06/k-pop-fans-hashtags-whitelivesmatter-bluelivesmatter/

Shimizu, K. (2020). 2019-nCoV, fake news, and racism. The Lancet, 395, 684-685. doi:10.1016/S0140-6736(20)30359-7

Stechemesser, A., Wenz, L., \& Anders, L. (2020). Corona crisis fuels racially profiled hate in social media networks. EClinical Medicine-The Lancet, 23, 100372. doi: 10.1016/j.eclinm.2020.100372

Townsend, M. (2020). Far-right thugs exploit Black Lives Matter movement, warns UK anti-extremism chief. The Guardian. Retrieved from https://www.theguardian.com/ world/2020/jun/28/far-right-thugs-exploit-black-lives-matter-movement-warns-ukanti-extremism-chief

UN Women. (2020). Impact of COVID-19 on violence against women and girls and service provision: UN women rapid assessment and findings. Retrieved from https://www.unwomen.org/en/digital-library/publications/2020/05/impact-of-covid19-on-violence-against-women-and-girls-and-service-provision

Wilke, C. (2020). Trump cranks up attacks on the Black Lives Matter movement for racial justice. CNBC. Retrieved from https://www.cnbc.com/2020/06/25/trumpattacks-black-lives-matter-racial-justice-movement.html

Zoom. (2020). Privacy and security. Retrieved from https://zoom.us/docs/en-us/ covid19.html\#security 